\title{
Bridgehead vicinal diallylation of norbornene derivatives and extension to propellane derivatives via ring-closing metathesis
}

\author{
Sambasivarao Kotha ${ }^{\star} \S$ and Rama Gunta
}

\author{
Full Research Paper \\ Address: \\ Department of Chemistry, Indian Institute of Technology-Bombay, \\ Powai, Mumbai, India \\ Email: \\ Sambasivarao Kotha* - srk@chem.iitb.ac.in \\ * Corresponding author \\ $\S$ Fax: 022-25767152 \\ Keywords: \\ norbornene; propellane derivatives; ring-closing metathesis; \\ single-crystal X-ray diffraction; vicinal diallylation
}

\author{
Beilstein J. Org. Chem. 2016, 12, 1877-1883. \\ doi:10.3762/bjoc.12.177 \\ Received: 17 May 2016 \\ Accepted: 03 August 2016 \\ Published: 22 August 2016 \\ Associate Editor: I. Marek \\ (c) 2016 Kotha and Gunta; licensee Beilstein-Institut. \\ License and terms: see end of document.
}

\begin{abstract}
Here, we report a simple synthetic strategy to the bridgehead vicinal diallylation of norbornene derivatives. These substrates are useful to generate propellanes via ring-closing metathesis. Single-crystal X-ray diffraction analysis of four compounds led to the realization of configurational correction of earlier reported molecules.
\end{abstract}

\section{Introduction}

The norbornene moiety is a useful template and also a versatile synthon in organic synthesis [1]. The double bond present in the norbornene frame is strained and therefore participates in cycloaddition sequences as a $\mathrm{C}_{2}$-synthon [2,3]. It was reported that the norbornene system is as strained as cyclopropane or cyclobutane (norbornene, $100 \mathrm{~kJ} / \mathrm{mol}$; cyclopropane, $115 \mathrm{~kJ} / \mathrm{mol}$; cyclobutane, $110 \mathrm{~kJ} / \mathrm{mol}$ ) [4,5]. Some of the annulated norbornene derivatives undergo retro Diels-Alder (rDA) reactions at ambient temperature in the presence of methylaluminium dichloride and a reactive dienophile [6-8]. Cage compounds with interesting applications have been assembled by a cyclization reaction starting with suitably functionalized norbornene derivatives [9-11]. Moreover, the norbornene unit induces a hairpin-like architecture when it is incorporated into a peptide chain. This property is useful to design norbornenebased ionophores [12]. Due to the strained nature of norbornene systems they are useful precursors for ring-rearrangement metathesis (RRM) [13-21] to generate intricate polycyclics involving non-traditional retrosynthetic routes. Recently, functionalization of unactivated aromatic $\mathrm{C}-\mathrm{H}$ bonds was achieved by using palladium catalysts and norbornene (Catellani reaction) $[22,23]$. In view of these applications, the design and synthesis of vicinal diallylnorbornene derivatives is a worthwhile exercise. The double bond present in the allyl group can be further 
converted into various other useful functionalities for further synthetic manipulation by adopting the appropriate functional group transformations.

\section{Strategy}

Our approach to various propellane derivatives is shown in Figure 1. The target propellane 1 could be assembled from diallyl compound $\mathbf{2}$ via ring-closing metathesis (RCM) [24-32]. Whereas, the diallyl derivative 2 can be derived from a readily available Diels-Alder (DA) adduct $\mathbf{3}$ through an allylation sequence.

\section{Results and Discussion}

Installation of two $\mathrm{C}-\mathrm{C}$ bonds to generate quaternary centers in a stereocontrolled manner in a single step is not a trivial exercise. Generally, it was accomplished by radical three-component coupling reactions or Michael-type additions of organocopper reagents starting with conjugated carbonyl compounds $[33,34]$. But, the resulting alkyl groups are in trans orientation. Our journey to propellane 1 synthesis (Figure 1) was commenced with the preparation of known DA adducts $\mathbf{3 a}, \mathbf{3 b}, \mathbf{3} \mathbf{a} \mathbf{a}^{\prime}$ and 3bb' [35-37]. In this regard, DA adduct 3a was treated with allyl bromide in the presence of $\mathrm{NaH}$ to obtain the corresponding $O$-allylated compound (70\%) and $C$-allylated compound 2 a (28\%) by using our earlier reported method [38]. Next, diallyl compound 2a on RCM using Grubbs first generation (G-I) catalyst in $\mathrm{CH}_{2} \mathrm{Cl}_{2}$ at room temperature (rt) gave the desired propellane derivative 1a (61\%) along with a minor amount of quinone derivative 4 (17\%) (Scheme 1). The formation of quinone $4 \mathrm{can}$ be explained on the basis that compound $2 \mathbf{a}$ underwent rDA and RCM in one-pot. Here, the compound 2a didn't undergo RRM because a metallacyclobutane cannot be formed between the allyl and norbornene double bonds due to structural constraint [39] and moreover, we didn't observe any ring-opening metathesis (ROM) product during RCM reaction. This may be due to the fact that sparging with an inert gas $\left(\mathrm{N}_{2}\right.$ or Ar) during RCM process helps to accelerate the loss of ethylene and thus, prevents ROM [39].

Garratt and Hollowood reported that bridgehead functionalization of norbornene derivatives such as endo-5-norbornene-2,3dicarboximide 5 gave bridgehead alkylated compound 6 with retention of configuration (Scheme 2) [40]. Based on this report, we expected the allyl groups introduced via alkylation
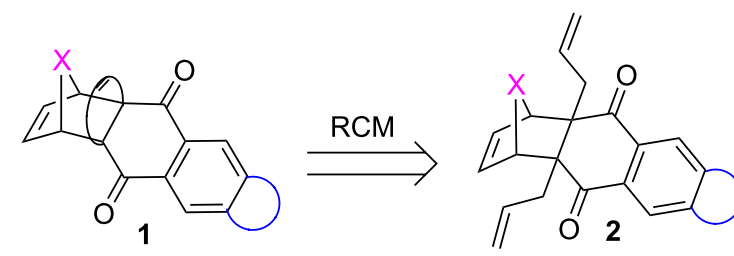
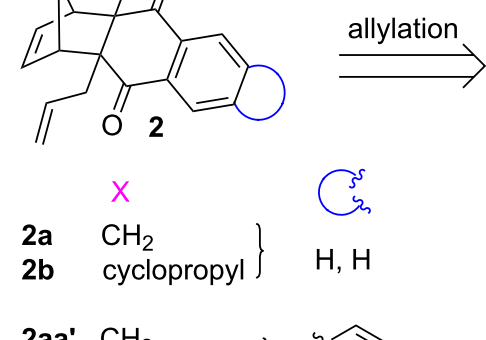

$\left.\begin{array}{ll}\mathbf{2} \mathbf{a} \mathbf{a}^{\prime} & \mathrm{CH}_{2} \\ \mathbf{2 b} \mathbf{b}^{\prime} & \text { cyclopropyl }\end{array}\right\}$<smiles>C1CCCCC1</smiles>

$\mathrm{H}, \mathrm{H}$<smiles>C1=CC=CCC=C1</smiles>

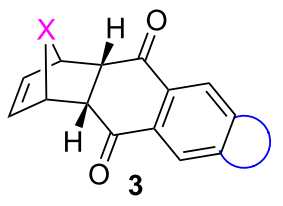

$3 a$

$3 \mathbf{b}$

3aa'

3bb'

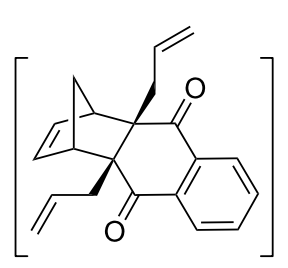

$2 a b$

earlier reported configuration

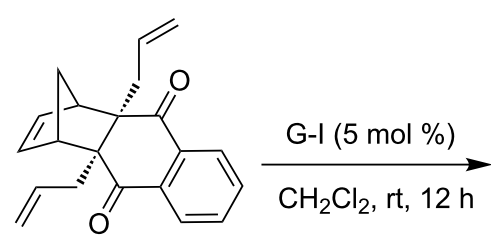

$2 \mathbf{a}$

revised configuration<smiles>O=C1CC2(C(=O)c3ccccc31)C1C=CC2C1</smiles>

$1 \mathrm{a}(61 \%)$<smiles>O=C1C2=C(CC=CC2)C(=O)c2ccccc21</smiles>

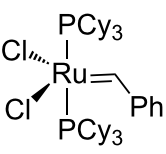

$4(17 \%)$ 

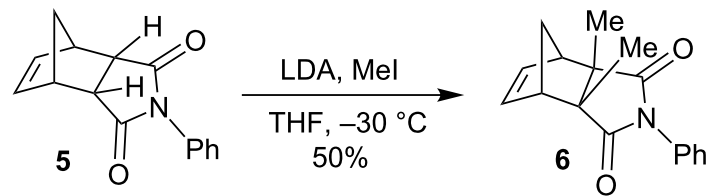

Scheme 2: Garratts work on alkylation of norbornene with retention of configuration.

sequence will occupy the exo position (see $\mathbf{2} \mathbf{a b}$ ) because the bridgehead hydrogens in DA adduct $\mathbf{3 a}$ are in exo configuration. Thus, in the final compound 1a the newly formed 6-membered ring during RCM is supposed to be in the exo configuration.

To our surprise, single-crystal X-ray analysis of 1a revealed that the 6-membered ring (C28-C30-C31-C32-C33-C27) formed via $\mathrm{RCM}$ is in endo configuration as depicted in Figure 2.

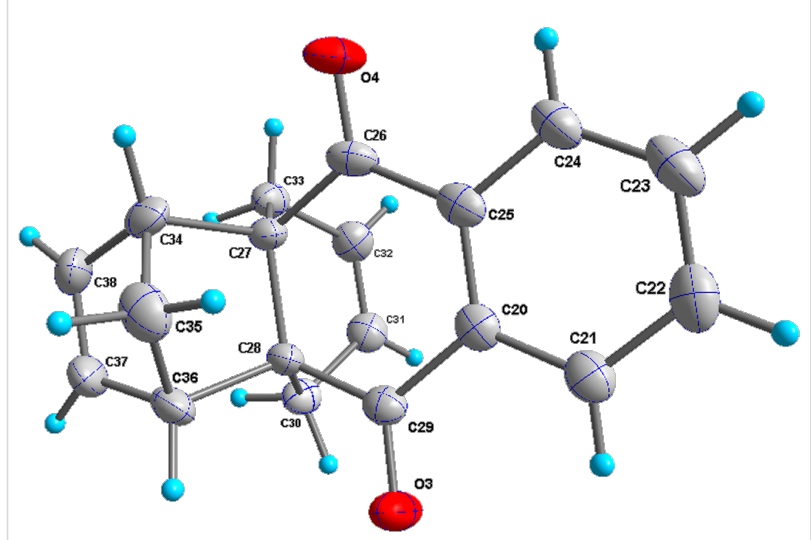

Figure 2: The molecular structure of 1a, with displacement ellipsoids drawn at the $50 \%$ probability level.

At this point, we turned our attention to understand the configurational origin of the allyl groups in $\mathbf{2 a}$. To understand whether compound 2a was formed by Claisen rearrangement (CR) of the corresponding $O$-allyl compound or by carbanion mediated $C$-allylation of the DA adduct 3a, we carried out the alkylation of compound 3a with $n$-propyl bromide in refluxing THF for
$2 \mathrm{~h}$. Here, di-O-propyl compound 7 was obtained in $36 \%$ yield along with a dehydrogenated compound 8 (20\%, Scheme 3$)$. Surprisingly, no $C$-alkylation product was observed from $3 \mathbf{a}$. This result suggests that the $C$-allyl compound 2a was formed from the corresponding $O$-allyl compound via $\mathrm{CR}$.

Based on the X-ray structure of $\mathbf{1 a}$ and the above observations, it is clear that the allyl groups in $\mathbf{2 a}$ are in endo configuration which can be explained as follows. Since the stereocenters are unaffected during the RCM sequence it is evident that the allyl groups present in $\mathbf{2 a}$ should be in endo configuration. To confirm the configuration of the allyl groups, the X-ray structure of previously reported oxa-bowl/propellane hybrid (15) [38] was also recorded and it is in agreement with the above findings (Figure 3). These results suggested the revision of earlier reported configuration of allyl groups. More specifically, various compounds (2ab, 2aa'b and $\mathbf{9 a - 1 5 a ) ~ r e p o r t e d ~ i n ~ o u r ~}$ previous report [38] need configurational correction and the revised structures (2aa' and 9-15) are included in Table 1.

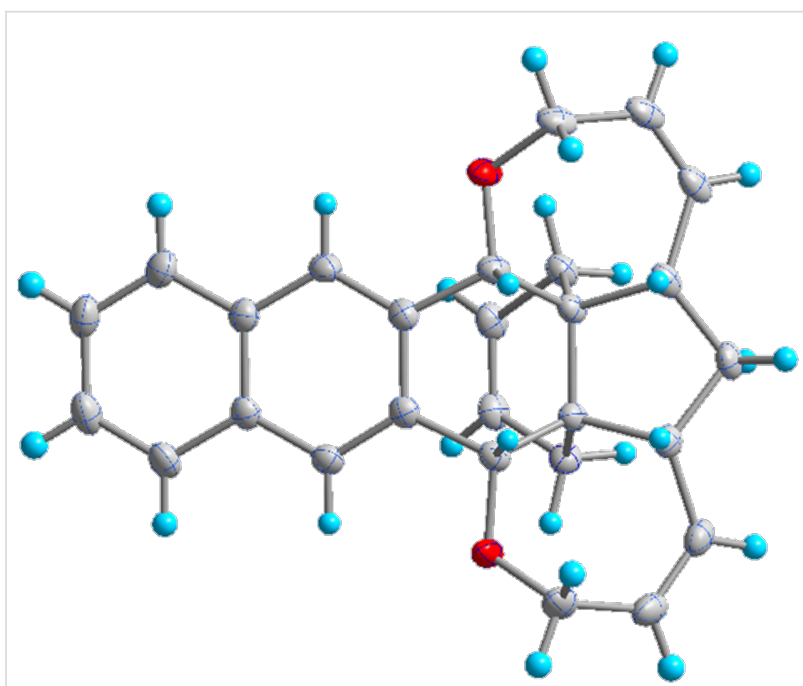

Figure 3: Crystal structure of compound 15 showing $50 \%$ displacement ellipsoids.

When the other previously prepared diallyl compound 2aa' [38] was subjected to RCM using G-I catalyst under similar reaction

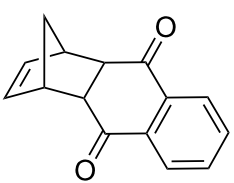

$3 a$

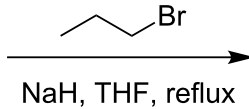

$2 \mathrm{~h}$

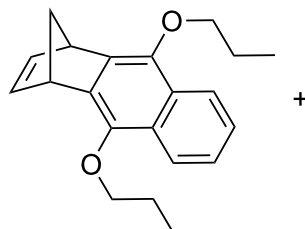

$7(36 \%)$

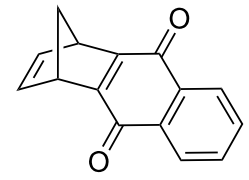

$8(20 \%)$

Scheme 3: Control experiment carried out to probe the configuration of $2 a$. 
Table 1: Revised structures from our previous work [38] with correct configuration.

$\begin{array}{llll}\text { Entry } & \text { Revised structures } \quad \text { Earlier reported structures Entry } \quad \text { Revised structures } \quad \text { Earlier reported structures }\end{array}$
(ref. [38]) (ref. [38])

1

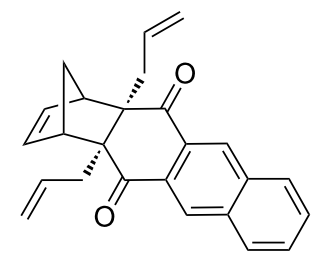

2aa'

2<smiles>C=C[C@@H]1C[C@H](C=C)[C@@]2(C)C(=O)c3ccccc3C(=O)[C@]12C</smiles>

3

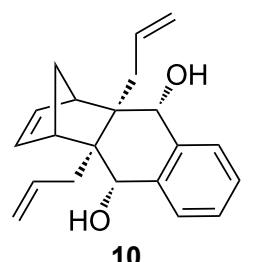

4

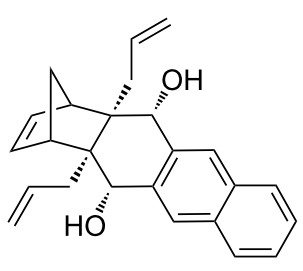

11

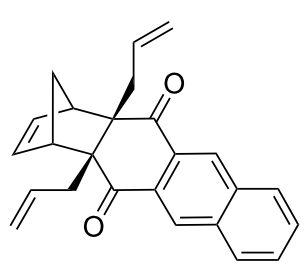

2aa'b
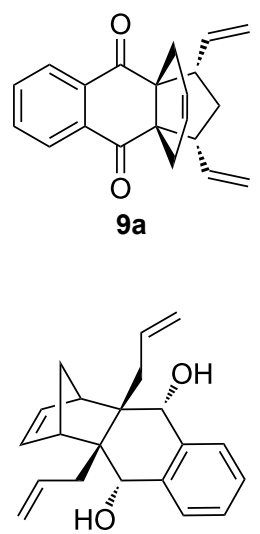

10a

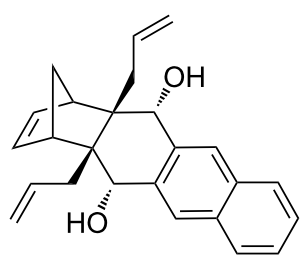

$11 a$
5

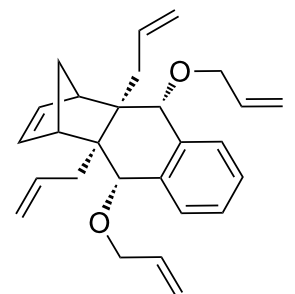

12

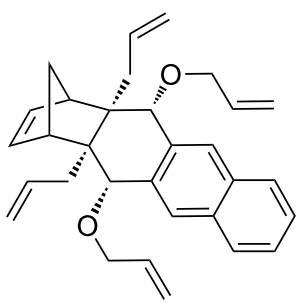

13

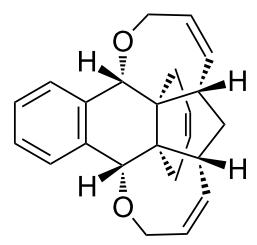

14

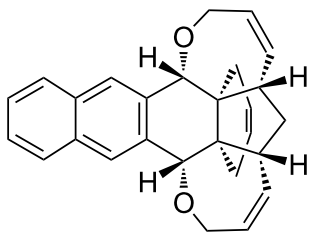

15

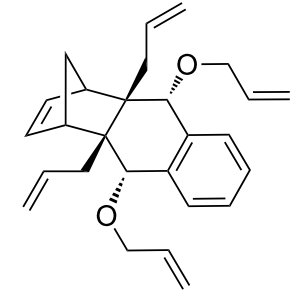

$12 a$

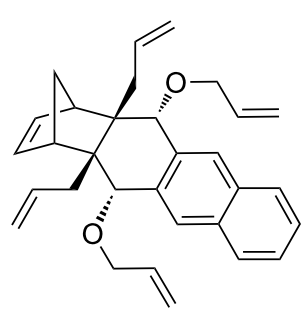

$13 a$

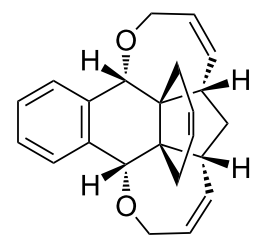

$14 a$

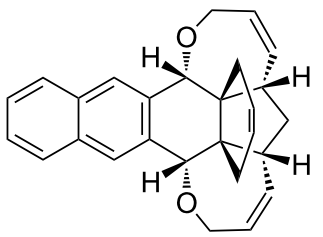

$15 a$ conditions the propellane derivative 1aa' was obtained in 79\% yield (Scheme 4).

To expand the scope of this strategy, cyclopropyl containing diallyl products $\mathbf{2} \mathbf{b}$ and $\mathbf{2} \mathbf{b} \mathbf{b}^{\prime}$ were also prepared along similar lines starting with the corresponding DA adducts $\mathbf{3 b}$ and $\mathbf{3} \mathbf{b} \mathbf{b}^{\prime}$ [41]. Initially, the diallyl compound $\mathbf{2 b}$ was reacted with G-I catalyst to afford the desired propellane $\mathbf{1 b}$ in $86 \%$ yield (Scheme 5). Its structure has been established on the basis of spectroscopic data $\left({ }^{1} \mathrm{H}\right.$ NMR, ${ }^{13} \mathrm{C}$ NMR and DEPT-135) and was further supported by HRMS data.

In addition, the configuration of $\mathbf{1 b}$ and $\mathbf{2} \mathbf{b}$ were unambiguously determined via single-crystal X-ray diffraction analysis
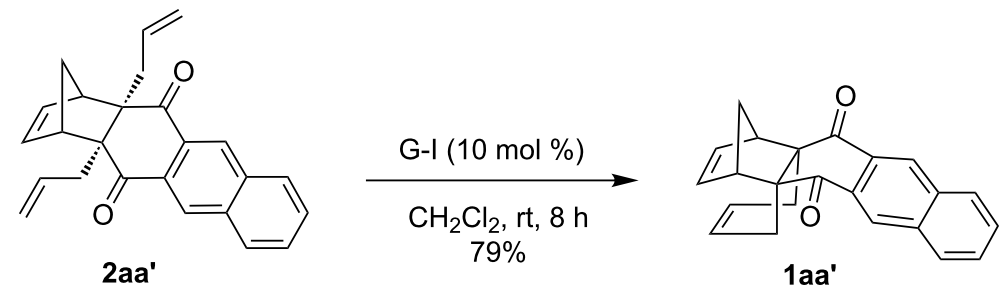

Scheme 4: RCM of the compound 2aa'. 


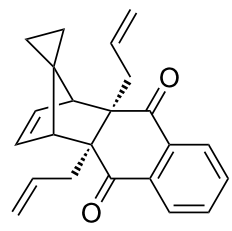

2b

\section{$\underset{\mathrm{CH}_{2} \mathrm{Cl}_{2}, \mathrm{rt}, 20 \mathrm{~h}}{\stackrel{\mathrm{G}-\mathrm{I}}{(5 \mathrm{~mol} \%)}}$ $86 \%$}

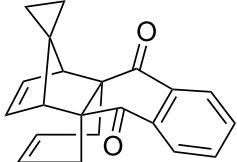

1b
Scheme 5: RCM approach to the propellane derivative $\mathbf{1 b}$.

(Figure 4). Based on this data it is clear that the bridgehead allyl groups in the RCM precursor $\mathbf{2 b}$ are in endo configuration. Subsequent RCM of diallyl compound $\mathbf{2 b}$ gave the ring-closing product $\mathbf{1 b}$ with retention of the configuration.

Similarly, staring with substrate $\mathbf{2} \mathbf{b} \mathbf{b}$ ', another propellane derivative $\mathbf{1 b b}$ ' was synthesized using the same catalyst (i.e., G-I) in $\mathrm{CH}_{2} \mathrm{Cl}_{2}$ at rt. Here, along with the desired propellane $\mathbf{1} \mathbf{b b}$ (79\%) a minor amount of quinone derivative $\mathbf{1 6}(13 \%)$ was also generated due to a one-pot RCM-rDA sequence of $\mathbf{2} \mathbf{b b}^{\prime}$ which is similar to the substrate $\mathbf{2 a}$ (Scheme 6). Compound $\mathbf{1} \mathbf{b b}$ ' was characterized based on the ${ }^{1} \mathrm{H}$ and ${ }^{13} \mathrm{C}$ NMR, DEPT-135 and further supported by HRMS data. However, spectroscopic data of quinone $\mathbf{1 6}$ were identical with the literature values [41].

\section{Conclusion}

This methodology was found to be useful to synthesize various propellane derivatives containing a norbornene moiety by employing RCM sequence. Moreover, we have firmly established the configuration of allyl groups at bridgehead position of norbornene derivatives by single-crystal X-ray diffraction analysis. A control experiment with propyl bromide provided an insight into the reaction mechanism that the bridgehead allylation proceeds through enolization, $O$-allylation followed by $\mathrm{CR}$ and not via carbanion chemistry. This alternative strategy is useful to introduce vicinal diallyl groups in a cis orientation to generate propellane derivatives, which is a different protocol from previously reported methods where the two vicinal alkyl groups are introduced in trans orientation. In this study, we have also revised the configuration of our earlier reported molecules containing allyl groups and oxa-bowl/propellane hybrids. Since non-flattened molecules are implicated in biological systems, our results would be useful in drug design [42].
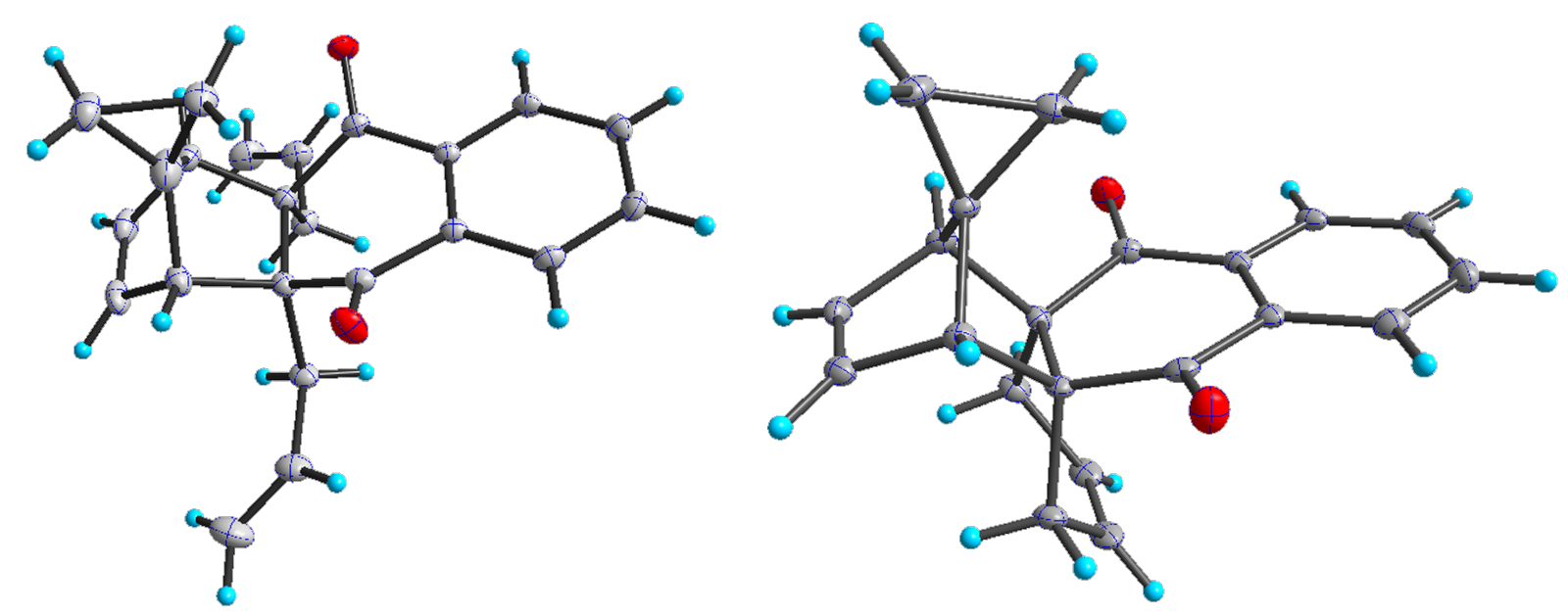

Figure 4: The molecular structures of the compounds $\mathbf{2 b}$ (left) and $\mathbf{1 b}$ (right) showing $30 \%$ displacement ellipsoids.

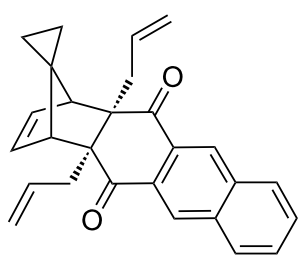

2bb'

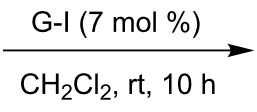

$\mathrm{CH}_{2} \mathrm{Cl}_{2}, \mathrm{rt}, 10 \mathrm{~h}$

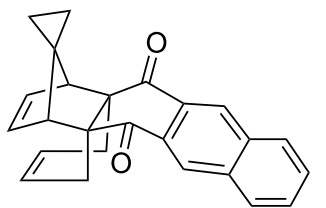

1bb' (79\%)<smiles>O=C1C2=C(CC=CC2)C(=O)c2cc3ccccc3cc21</smiles>

$16(13 \%)$ 


\section{Supporting Information}

Crystallographic data have been deposited with the Cambridge Crystallographic Data Centre (CCDC) as supplementary publication numbers CCDC 1475412 (1a), 1475453 (1b), 1475403 (2b) and 1451438 (15). Copies of the data can be obtained free of charge on application to the Director at CCDC, 12 Union Road, Cambridge CB2 1EZ, UK (FAX: (+44) 1223-336-033; email:

deposit@ccdc.cam.ac.uk).

\section{Supporting Information File 1}

Experimental procedures, characterization data, copies of ${ }^{1} \mathrm{H} \&{ }^{13} \mathrm{C}$ NMR for all new compounds and X-ray data of the compounds $\mathbf{1 a}, \mathbf{1 b}, \mathbf{2 b}$ and $\mathbf{1 5}$.

[http://www.beilstein-journals.org/bjoc/content/ supplementary/1860-5397-12-177-S1.pdf]

\section{Supporting Information File 2}

Crystallographic information files of compounds $\mathbf{1 a}$ (CCDC 1475412), 1 b (CCDC 1475453), 2 b (CCDC 1475403) and 15 (CCDC 1451438).

[http://www.beilstein-journals.org/bjoc/content/ supplementary/1860-5397-12-177-S2.zip]

\section{Acknowledgements}

We thank the Department of Science and Technology (DST), New Delhi for the financial support and also thank Darshan Mhatre for his help in collecting the X-ray data and structure refinement. S. K. thanks the Department of Science and Technology for the award of a J. C. Bose fellowship and Praj industries for Chair Professorship (Green Chemistry). R. G. thanks the University Grants Commission (UGC), New Delhi for the award of a research fellowship.

\section{References}

1. Ghosh, S.; Banerjee, S. ARKIVOC 2002, No. vii, 8-20.

2. Thansandote, P.; Hulcoop, D. G.; Langer, M.; Lautens, M. J. Org. Chem. 2009, 74, 1673-1678. doi:10.1021/jo802604g

3. Parham, M. E.; Frazer, M. G.; Bradsher, C. K. J. Org. Chem. 1972, 37, 358-362. doi:10.1021/jo00968a005

4. Engler, E. M.; Andose, J. D.; Schleyer, P. V. R. J. Am. Chem. Soc. 1973, 95, 8005-8025. doi:10.1021/ja00805a012

5. North, M. ROMP of Norbornene Derivatives of Amino Esters and Amino Acids. In Ring Opening Metathesis Polymerisation and Related Chemistry: State of the Art and Visions for the New Century; Khosravi, E.; Szymanska-Buzar, T., Eds.; Kluwer Academic: Dordrecht, Netherlands, 2002; pp 157-166.

6. Eddolls, J. P.; lqbal, M.; Roberts, S. M.; Santoro, M. G. Tetrahedron 2004, 60, 2539-2550. doi:10.1016/j.tet.2004.01.047

7. Grieco, P. A.; Abood, N. J. Org. Chem. 1989, 54, 6008-6010. doi:10.1021/j000287a005
8. Kotha, S.; Banerjee, S. RSC Adv. 2013, 3, 7642-7666. doi:10.1039/c3ra22762f

9. Wu, H.-J.; Tsai, S.-H.; Chern, J.-H.; Lin, H.-C. J. Org. Chem. 1997, 62, 6367-6373. doi:10.1021/jo970348I

10. Masusai, C.; Soorukram, D.; Kuhakarn, C.; Tuchinda, P.; Pakawatchai, C.; Saithong, S.; Reutrakul, V.; Pohmakotr, M. J. Org. Chem. 2015, 80, 1577-1592. doi:10.1021/jo502501v

11. Kotha, S.; Dipak, M. K. Chem. - Eur. J. 2006, 12, 4446-4450. doi:10.1002/chem.200501366

12. Ranganathan, D.; Haridas, V.; Kurur, S.; Nagaraj, R.; Bikshapathy, E.; Kunwar, A. C.; Sarma, A. V. S.; Vairamani, M. J. Org. Chem. 2000, 65, 365-374. doi:10.1021/jo9912045

13. Holub, N.; Blechert, S. Chem. - Asian J. 2007, 2, 1064-1082. doi:10.1002/asia.200700072

14. Kotha, S.; Meshram, M.; Khedkar, P.; Banerjee, S.; Deodhar, D. Beilstein J. Org. Chem. 2015, 11, 1833-1864. doi:10.3762/bjoc.11.199

15. Malik, C. K.; Yadav, R. N.; Drew, M. G. B.; Ghosh, S. J. Org. Chem. 2009, 74, 1957-1963. doi:10.1021/jo802077t

16. Kotha, S.; Gunta, R. Beilstein J. Org. Chem. 2015, 11, 1373-1378. doi:10.3762/bjoc. 11.148

17. Kotha, S.; Ravikumar, O. Beilstein J. Org. Chem. 2015, 11 , 1259-1264. doi:10.3762/bjoc. 11.140

18. Kotha, S.; Ravikumar, O. Eur. J. Org. Chem. 2014, 5582-5590. doi:10.1002/ejoc.201402273

19. Funel, J.-A.; Prunet, J. Synlett 2005, 235-238. doi:10.1055/s-2004-837200

20. Kiss, L.; Kardos, M.; Forró, E.; Fülöp, F. Eur. J. Org. Chem. 2015, 2015, 1283-1289. doi:10.1002/ejoc.201403493

21. Bose, S.; Ghosh, M.; Ghosh, S. J. Org. Chem. 2012, 77, 6345-6350. doi:10.1021/jo300945b

22. Zhu, H.; Ye, C.; Chen, Z. Chin. J. Org. Chem. 2015, 35, 2291-2300. doi:10.6023/cjoc201505035

23. Han, J.; Zhang, L.; Zhu, Y.; Zheng, Y.; Chen, X.; Huang, Z.-B.; Shi, D.-Q.; Zhao, Y. Chem. Commun. 2016, 52, 6903-6906. doi:10.1039/C6CC02384C

24. Grubbs, R. H.; O'Leary, D. J., Eds. Handbook of Metathesis: Applications in Organic Synthesis, 2nd ed.; Wiley-VCH: Weinheim, Germany, 2015; Vol. 2.

25. Cossy, J.; Arseniyadis, S.; Meyer, C., Eds. Metathesis in Natural Product Synthesis: Strategies, Substrates and Catalysts; Wiley-VCH: Weinheim, Germany, 2010.

26. Grela, K., Ed. Olefin Metathesis: Theory and Practice; John Wiley \& Sons: Hoboken, NJ, U.S.A., 2014.

27. Kotha, S.; Krishna, N. G.; Halder, S.; Misra, S. Org. Biomol. Chem. 2011, 9, 5597-5624. doi:10.1039/c1ob05413a

28. Kotha, S.; Mandal, K.; Deb, A. C.; Banerjee, S. Tetrahedron Lett. 2004, 45, 9603-9605. doi:10.1016/j.tetlet.2004.11.012

29. Kotha, S.; Mandal, K.; Tiwari, A.; Mobin, S. M. Chem. - Eur. J. 2006, 12, 8024-8038. doi:10.1002/chem.200600540

30. Kotha, S.; Mandal, K. Tetrahedron Lett. 2004, 45, 1391-1394. doi:10.1016/j.tetlet.2003.12.075

31. Prunet, J. Eur. J. Org. Chem. 2011, 3634-3647. doi:10.1002/ejoc.201100442

32. Ghosh, S.; Ghosh, S.; Sarkar, N. J. Chem. Sci. 2006, 118, 223-235. doi:10.1007/Bf02708281

33. Keck, G. E.; Kordik, C. P. Tetrahedron Lett. 1993, 34, 6875-6876. doi:10.1016/S0040-4039(00)91818-5

34. Perlmutter, P. Conjugate Addition Reactions in Organic Synthesis; Pergamon Press: Oxford, United Kingdom, 1992. 
35. Valderrama, J. A.; Espinoza, O.; González, M. F.; Tapia, R. A.; Rodríguez, J. A.; Theoduloz, C.; Schmeda-Hirschmann, G. Tetrahedron 2006, 62, 2631-2638. doi:10.1016/j.tet.2005.12.038

36. Patney, H. K.; Paddon-Row, M. N. Synthesis 1986, 1986, 326-328. doi:10.1055/s-1986-31602

37. Singh, V.; Raju, B. N. S. Indian J. Chem. 1996, 35B, 303-311.

38. Kotha, S.; Gunta, R. Beilstein J. Org. Chem. 2015, 11, 1727-1731. doi:10.3762/bjoc. 11.188

39. van Lierop, B. J.; Lummiss, J. A. M.; Fogg, D. E. In Olefin Metathesis: Theory and Practice; Grela, K., Ed.; John Wiley \& Sons: Hoboken, NJ, U.S.A., 2014; pp 85-152. doi:10.1002/9781118711613.ch3

40. Garratt, P. J.; Hollowood, F. J. Org. Chem. 1982, 47, 68-72. doi:10.1021/jo00340a014

41. Kotha, S.; Gunta, R. Tetrahedron Lett. 2016, 57, 3021-3023. doi:10.1016/j.tetlet.2016.05.101

42. Torres, E.; Leiva, R.; Gazzarrini, S.; Rey-Carrizo, M.; Frigolé-Vivas, M.; Moroni, A.; Naesens, L.; Vázquez, S. ACS Med. Chem. Lett. 2014, 5, 831-836. doi:10.1021/ml500108s

\section{License and Terms}

This is an Open Access article under the terms of the Creative Commons Attribution License (http://creativecommons.org/licenses/by/4.0), which permits unrestricted use, distribution, and reproduction in any medium, provided the original work is properly cited.

The license is subject to the Beilstein Journal of Organic Chemistry terms and conditions:

(http://www.beilstein-journals.org/bjoc)

The definitive version of this article is the electronic one which can be found at: doi:10.3762/bjoc. 12.177 